\title{
Reliability Evaluation of Wastewater Treatment Plant Impact on the Receiving Waters
}

\author{
Dariusz Andraka ${ }^{1}$ \\ 1 Bialystok University of Technology, Faculty of Civil and Environmental Engineering, Wiejska 45E, \\ 15-351 Bialystok, Poland \\ e-mail: d.andraka@pb.edu.pl
}

\begin{abstract}
The paper presents the results of the study on reliability of the "Wastewater Treatment Plant (WWTP) - Receiver" system, using different models for predicting probability that the river will stay in the required purity class after receiving the discharge from a WWTP. A probabilistic model based on the total probability theorem and Monte Carlo (MC) simulations of the water quality below the wastewater discharge were used. The results show that probabilistic model generates lower values of "WWTP-Receiver" system's reliability than the MC simulations. The results from the MC model may give more realistic values, being able to reflect the stochastic nature of the process, also showing that for the overall reliability of the "WWTP-Receiver" system - the quality of the receiver is a more sensitive factor than the WWTP's reliability.
\end{abstract}

Keywords: reliability, wastewater treatment, wastewater receiver, water purity class

\section{INTRODUCTION}

The reliability of a wastewater treatment plant (WWTP) is a complex research problem that has been of interest to scientists for many years. It should be noted that the majority of WWTPs are characterized by a complex technological system, which consists of several technological units that implement various stages of the wastewater treatment process and are combined at series-parallel or parallel-series or mixed reliability structure. An additional complication from the point of view of reliability tests is the fact that the main technological unit - the biological reactor - uses a variety of microorganism cultures, whose activity depends on a number of external factors, independent of the plant operator (quality and quantity of treated sewage, atmospheric conditions, etc.). Therefore, the classic reliability examination methods, which are based on the analysis of reliability block diagrams and determination of typical reliability factors (intensity of failure, mean time between failures/to repair - MTBF/MTTR, renewal time, reliability function) are rarely used here. The methods most often used in assessing the reliability of WWTP include:

- method introducing an additional factor the coefficient of reliability (COR), allowing for the estimation of probability of obtaining the required technological efficiency [Niku et al., 1979];

- cause-and-effect analysis methods, including the fault tree analysis (FTA) [Taheriyoun and Moradinejad 2015, Kelley and Allison, 1981; Andraka, 2009];

- stochastic methods, including time series analysis [Berthouex and Box, 1996; Ayesha et al., 2013].

Particularly noteworthy is the COR method, which allows to estimate the technological reliability of the treatment plant based on the statistical properties of random variable such as quality of sewage discharged from WWTP (mean, standard deviation, cumulative distribution / probability distribution) and required level of contaminants in the discharge from the plant. This method is, among others, recommended for use by the US 
EPA [Niku et al., 1981] and recognized in the technical literature [Tchobanoglous et al., 2003].

It should also be remembered that the wastewater treatment plant is not an isolated object and its efficiency should also be considered in the context of impact on the receiving waters. The carried out studies on the interdependence of the WWTP - Receiver system show that high reliability of the treatment plant does not always guarantee no adverse impact on the receiver and the discharge from WWTP may cause significant deterioration of the of receiver's water quality (resulting in a change of purity class) [Rak and Wieczysty, 1997; Andraka and Dzienis, 2013; Rak and Pietrucha-Urbanik, 2019]. Improving the knowledge about this relationship was the main motivation to undertake the research presented in this paper.

\section{MATERIALS AND METHODS}

In this research, two different approaches related to the qualitative assessment of uncertain phenomena were used:

- probabilistic assessment of the event that the receiver will remain in the current purity class (in accordance with applicable environmental protection regulations), based on the total probability theorem;

- stochastic assessment of the probability that the receiver will remain in the current purity class, based on the balance of pollutant loads in the receiver and Monte Carlo simulations.

\section{Total probability method}

One of the first attempts to assess the functioning of the WWTP-Receiver system, was the work of Rak and Wieczysty [1997], who proposed using the formula for the total probability of the event $\mathrm{P}(\mathrm{Y})$ defined as: "receiver will remain in the required purity class after discharging wastewater from WWTP":

$$
P(Y)=\sum_{i=1}^{n} P\left(Y \mid X_{i}\right) \cdot P\left(X_{i}\right)
$$

where: $X_{1}, X_{2}, \ldots, X_{n}$ - sequence of mutually comprehensive events, related in this case to the specific operating conditions of WWTP in terms of the pollutants load (quality of the inflow to WWTP), which are divided into the following categories of operating conditions:

$X_{1}$ - "standard" operation of WWTP - the quality of the inflow corresponds to the design assumptions, the plant operates with the required efficiency;

$X_{2}$ - operation of WWTP with excessive load - the quality of the inflow exceeds the design assumptions, the plant can operate with the required efficiency under the condition of launching additional technological reserves (e.g. increasing the sludge age or recirculation rate, inclusion of an additional technological line etc.); $X_{3}$ - operation of WWTP with a critical load - the quality of the inflow far exceeds the assumptions, in most cases the plant is not able to obtain the required technological effect;

$P\left(X_{i}\right)$ - probability that WWTP is in the category $X_{\mathrm{i}}$ of operating conditions;

$P(Y \mid X)$ - probability that the receiver will remain in the required purity class, provided that the plant is in category $\mathrm{X}_{\mathrm{i}}$ of the operating conditions, it is assumed to be a conjunction of three events:

$$
P\left(Y \mid X_{i}\right)=A_{i} \cdot P\left(H_{i}\right) \cdot P_{r}
$$

where: $A_{i}$ - availability of WWTP in the i-th category of technological conditions;

$P\left(H_{i}\right)$ - human reliability, defined as the probability that the operator will undertake right technological decision in the i-th category of operational conditions, $P_{r}-$ reliability of the receiver, defined as probability; that the river is in the required purity class.

The research presented in this paper is based on the following assumptions regarding the parametersandindicesincluded in the equations(1) and (2):

- assuming that the WWTP was designed in accordance with the ATV -A131 rules [Bever et al., 1997, ATV-DVWK, 200], which is not only Polish but also European-wide practice, the required technological effect should be achieved in $85 \%$ of influent loads to the plant ("standard" conditions, category $\mathrm{X}_{1}$ ); in $10 \%$ of cases - the plant can receive additional loads that, however, allow achieving a technological effect $\left(\mathrm{X}_{2}\right)$, while in the remaining $5 \%$ of cases - the influent load prevents obtaining the required technological effect $\left(\mathrm{X}_{3}\right)$; thus: $\mathrm{P}\left(\mathrm{X}_{1}\right)=0.85 ; \mathrm{P}\left(\mathrm{X}_{2}\right)=0.10 ; \mathrm{P}\left(\mathrm{X}_{3}\right)=0.05$; 
- the availability of WWTP, unlike in the original research of Rak and Wieczysty [1997], was estimated using COR method [Niku et al., 1979], assuming that the availability defined by the formula (3), which is the ratio of the length of operating periods in which the plant worked as required (time ${ }_{\text {up }}$ ) in the examined period to the total time of observations [Smith, 2011], refers to the same value as the WWTP reliability calculated as empirical probability:

$$
A=\frac{\text { time }_{u p}}{\text { time }_{\text {up }}+\text { time }_{\text {down }}}
$$

- additionally, in all simulations it was assumed that the quality indicators of the treated wastewater have a log-normal distribution, which was confirmed by numerous studies [Niku and Shroeder, 1981; Berthouex, and Hunter, 1983; Oliveira and V. Sperling, 2008], then the following formula can be used:

$$
Z_{A}=\frac{-\ln \left(\frac{C O R}{\sqrt{C O V^{2}+1}}\right)}{\sqrt{\ln \left(C O V^{2}+1\right)}} \wedge \Phi\left(Z_{A}\right)=A
$$

where: $Z_{A}-$ the value of a standardized random variable that corresponds to the level of reliability (availability) $\mathrm{A}$;

COR - coefficient of reliability, which is the ratio of the mean value of the considered wastewater quality indicator to the limit value of this indicator in the effluent from the plant; taking into account the categories of operating conditions $\left(\mathrm{X}_{\mathrm{i}}\right)$ considered in the third model, it was assumed:

$\mathrm{COR}_{1}=0.5$ for WWTP operating under "standard" conditions,
$\mathrm{COR}_{2}=1.0$ for WWTP operating at increased load,

$\mathrm{COR}_{3}=1.5$ for WWTP operating under "critical" conditions;

$\mathrm{COV}$ - coefficient of variation, which is the ratio of the standard deviation to the average value of the considered random variable;

$\Phi\left(Z_{A}\right)$ - value of the cumulative distribution function (CDF) of the random variable $\mathrm{Z}_{\mathrm{A}}$, of standard normal distribution.

- human reliability factor was estimated according to Rak and Wieczysty [1997]:

- $\mathrm{P}\left(\mathrm{C}_{1}\right)=0.9998$ for WWTP operating under "standard" conditions,

- $\mathrm{P}\left(\mathrm{C}_{2}\right)=0.9985$ for WWTP operating at increased load,

- $\mathrm{P}\left(\mathrm{C}_{3}\right)=0.995$ for WWTP operating under "critical" conditions;

- the receiver's reliability was assumed hypothetically, but following the hydrological tests carried out for one of the rivers of north-eastern Poland; the variability of flow and concentration of $\mathrm{BOD}_{5}$ in the river is presented in Figure 1, which shows that the river adopted for the model is characterized by "reliability" at the level of 0.92 (i.e. that the probability that the $\mathrm{BOD}_{5}$ concentrations in the river will not exceed the limit value $6.0 \mathrm{mg} / \mathrm{dm}^{3}$ is $92 \%$ )

\section{Monte Carlo simulations}

The Monte Carlo simulations were used for the commonly accepted model of pollution concentration in the river after wastewater discharge, in the cross-section of full mixing, analogous to the research described by Andraka and Dzienis [2013]:
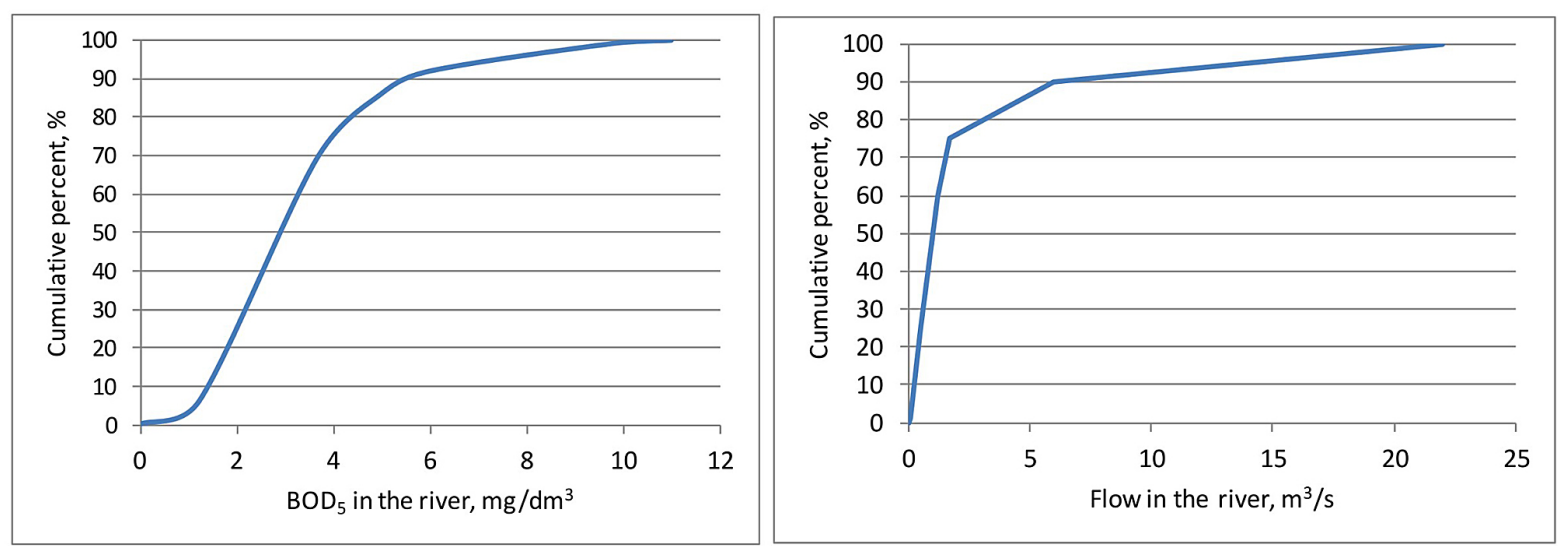

Fig. 1. Cumulative distribution function $(\mathrm{CDF})$ for the flow and the $\mathrm{BOD}_{5}$ concentration in the river 


$$
S_{r e c}=\frac{S_{W W T} \cdot Q_{W W T}+S_{r} \cdot Q_{r}}{Q_{W W T}+Q_{r}}
$$

where: $S_{\text {rec }}$ - concentration of a specified wastewater quality indicator in the river below the discharge of sewage;

$S_{W W T}$ - concentration of a specified wastewater quality indicator in the effluent from the WWTP;

$Q_{W W T}$ - the volumetric discharge from the WWTP;

$S_{r}$ - concentration of a specified water quality indicator in the river above the discharge from the WWTP;

$Q_{\mathrm{r}}$ - volumetric flow in the river above the discharge.

Because all the parameters appearing in equation (5) are random variables of a dynamic nature (variable in time), the applied Monte Carlo simulation seems to be a proper tool allowing to reduce the uncertainty associated with the current values of parameters used in the model.

The hypothetical wastewater treatment plant was used for the analysis. The reliability of WWTP is described by the model based on the COR index and the assumption about the lognormal distribution of the quality of the treated wastewater. In order to create a model of cumulative distribution, it was assumed that $\mathrm{COR}=0.6$ for the modeled plant (which is the weighted average of $\mathrm{COR}_{1}, \mathrm{COR}_{2}$ and $\mathrm{COR}_{3}$ used in the model 2.1). The required value of pollutant concentration in the treated wastewater was determined in accordance with the applicable regulations, as for a treatment plant of 10,000 PE.
The quantity of discharge from the WWTP was modeled assuming a lognormal distribution, with an average discharge equal to $10 \%$ SNQ (average of the lowest flows) which may be considered as a dilution that does not threaten the water quality of the receiver. An example cumulative distribution of $\mathrm{BOD}_{5}$ concentrations and the discharge from the plant for the coefficient of variation $\mathrm{COV}=0.3$ is shown in Figure 2.

For each set of parameters used in the model, three series of simulations were carried out including 3,000 runs each, which gives a total of 9,000 random runs of the model of the discharge from the WWTP mixing with river waters. The simulation results allowed to determine the following estimates:

$$
\begin{gathered}
P^{\prime}(Y)=P\left(S_{\text {rec }}<S_{r . \text { max }}\right) \\
P^{\prime}{ }_{W W T P}=P\left(S_{W W T}<S_{W W T \text { max }}\right) \\
P_{r}^{\prime}=P\left(S_{r}<S_{r . \text { max }}\right)
\end{gathered}
$$

from general formula for empirical probability:

$$
P^{\prime}(z<Z)=\frac{n_{z<Z}}{N}
$$

where: $P^{\prime}(Y)$ - estimate of WWTP-Receiver reliability;

$P_{\text {WWTP }}^{\prime}$ - estimate of WWTP reliability

$P_{r}^{\prime}$ - estimate of receiver's reliability

$S_{\text {rec }}, S_{W W T}, S_{\mathrm{r}}-$ as in eq. 5 ;

$S_{\text {r.max }}^{\text {rec }}$ - maximum concentration of a specified water quality indicator in the river, allowed for a given water purity class;
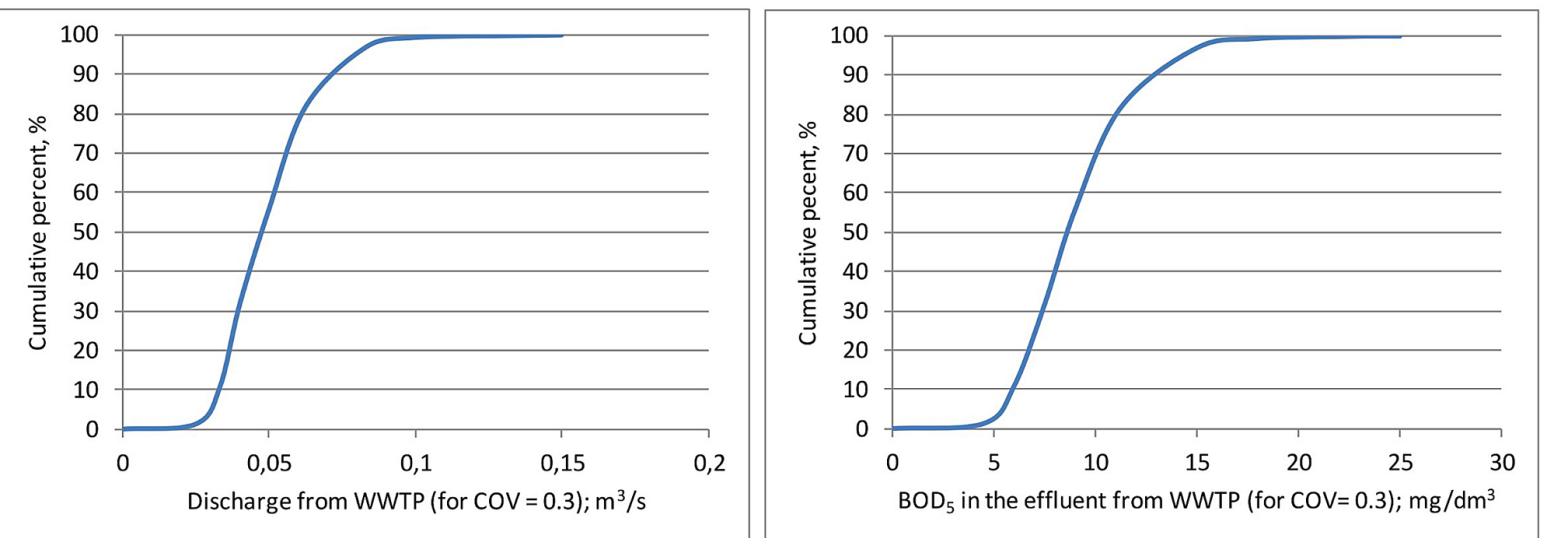

Fig. 2. Cumulative distribution function (CDF) for the discharge from WWTP and $\mathrm{BOD}_{5}$ in the effluent, coefficient of variation $\mathrm{COV}=0.3$ 
$S_{\text {WWT.max }}$ - maximum concentration of a specified water quality indicator in the effluent from the WWTP, allowed for a given plant;

$n_{z<Z}-$ number of runs where random variable $\mathrm{z}<\mathrm{Z}$;

$N$ - total number of runs.

\section{RESULTS AND DISCUSSION}

The simulations of the WWTP-Receiver system reliability were carried out using the models and equations described before for three variants of data sets with different statistical properties, characterized by a coefficient of variation $\mathrm{COV}=$ $0.3 ; 0.5$ and 0.7 . The simulations were carried out on the example of the $\mathrm{BOD}_{5}$ index, for which the limit values in the analyzed model were: $\mathrm{S}_{\mathrm{r} \text { max }}=$ $6 \mathrm{mg} / \mathrm{dm}^{3}$ for the river and $S_{\text {WWT.max }}=15 \mathrm{mg} / \mathrm{dm}^{3}$ for the treatment plant, respectively. The results obtained are summarized in Tables 1 and 2.

The results presented in the tables indicate a significant differentiation of the predicted reliability of the WWTP-Receiver system, depending on the method adopted for modeling the reliability of WWTP.

The lowest system's reliability was obtained from the total probability model with the highest COV value of the discharge. In this model, the significant influence of $\mathrm{COV}$ and the resulting reliability of the treatment plant (A) on the reliability of the entire system is also visible. This model is based on the conjunction of independent events affecting the quality of the treated wastewater and the quality of the receiver water; however, they do not take into account the dynamic nature of these phenomena. The model using Monte Carlo simulations seems to better characterize the behavior of the WWTP-Receiver system, because it takes into account the balance of pollutant loads in the river after the discharge from WWTP and thus can better describe the variability of pollutant loads in the river and treated sewage. However, it is interesting that the predicted reliability of the system does not depend on the COV of treated wastewater, although the results of the simulation show a significant decrease in the reliability of WWTP caused by increasing values of COV. This "unexpected" result of the simulations may be caused by the buffering capacity of the receiver (receiver with low concentration of pollutants may accept higher pollutants load) and shows that the receiver quality may be a deciding factor for the determination of the overall WWTP-Receiver system reliability.

\section{CONCLUSIONS}

The probabilistic models based on the statistical properties of random variables determining the quality of the treated wastewater or river waters are usually used for modeling the reliability of WWTP and forecasting water quality in a river. A similar approach can also be applied to the analysis of the WWTP-Receiver system, in which the probability of the river remaining in the required purity class is a conjunction of selected, independent random events. An alternative approach is to use the model of pollution load balance in the river accepting the discharge from WWTP, together with Monte Carlo simulations. The second method allows to capture the dynamic and stochastic nature of random variables used in the model.

Table 1. Reliability of the WWTP-Receiver system based on the total probability modelling

\begin{tabular}{|c|c|c|c|c|c|}
\hline \multirow{2}{*}{$\begin{array}{r}\text { State } \\
\text { of WWTP }\end{array}$} & \multicolumn{3}{|c|}{ Availability of WWTP. $A_{i}$} & \multirow{2}{*}{$P\left(H_{i}\right)$} & \multirow{2}{*}{$P_{r}$} \\
\hline & $\operatorname{COV}=0.3$ & $\operatorname{COV}=0.5$ & COV $=0.7$ & & \\
\hline$X_{1}$ & 0.993 & 0.956 & 0.921 & 0.9998 & \multirow{3}{*}{0.92} \\
\hline$X_{2}$ & 0.558 & 0.594 & 0.624 & 0.9985 & \\
\hline$X_{3}$ & 0.109 & 0.267 & 0.372 & 0.995 & \\
\hline--- & \multicolumn{3}{|c|}{$P\left(Y \mid X_{i}\right)$} & \multicolumn{2}{|c|}{$P(X)$} \\
\hline$x_{1}$ & 0.9134 & 0.8793 & 0.8472 & \multicolumn{2}{|c|}{0.85} \\
\hline$X_{2}$ & 0.5126 & 0.5457 & 0.5732 & \multicolumn{2}{|c|}{0.10} \\
\hline$X_{3}$ & 0.0998 & 0.2444 & 0.3405 & \multicolumn{2}{|c|}{0.05} \\
\hline \multicolumn{6}{|c|}{ Reliability of the system WWTP-Receiver. $P(Y)$} \\
\hline \multicolumn{2}{|c|}{$\operatorname{COV}=0.3$} & \multicolumn{2}{|c|}{$\operatorname{COV}=0.5$} & \multicolumn{2}{|c|}{$\operatorname{COV}=0.7$} \\
\hline \multicolumn{2}{|c|}{0.8326} & \multicolumn{2}{|c|}{0.8142} & \multicolumn{2}{|c|}{0.7944} \\
\hline
\end{tabular}


Table 2. Reliability of the WWTP-Receiver system based on the Monte Carlo simulations

\begin{tabular}{|c|c|c|c|c|c|}
\hline \multicolumn{6}{|c|}{ Reliability of the system WWTP-Receiver. $P^{\prime}(Y)$} \\
\hline \multicolumn{2}{|c|}{$\operatorname{COV}=0.3$} & \multicolumn{2}{|c|}{ COV $=0.5$} & \multicolumn{2}{|c|}{$C O V=0.7$} \\
\hline \multicolumn{2}{|c|}{0.8469} & \multicolumn{2}{|c|}{0.8547} & \multicolumn{2}{|c|}{0.8519} \\
\hline \multicolumn{6}{|c|}{ Model components } \\
\hline$P_{\text {WWTP }}^{\prime}$ & $P_{r}^{\prime}$ & $P_{\text {WWTP }}^{\prime}$ & $P_{r}^{\prime}$ & $P_{\text {WWTP }}^{\prime}$ & $P_{r}^{\prime}$ \\
\hline 0.966 & 0.918 & 0.908 & 0.925 & 0.810 & 0.922 \\
\hline
\end{tabular}

After the analysis of the results obtained within the presented study it can be concluded that the probabilistic model is more "conservative" and may give too low estimate of the reality. In turn, the Monte Carlo simulations seem to give more realistic results, being able to reflect varying in time loads of pollutants in the river and discharged wastewater. The results obtained from the MC model also show that the overall reliability of the WWTP-Receiver system is more sensitive to reliability (quality) of the river than the WWTP reliability. Owing to the buffering capacity of the river, decreasing reliability of WWTP (caused by "unstable" operational conditions characterized by higher COV values) does not result in a significant decrease in the WWTP-Receiver reliability, which remains on a relatively stable level.

\section{Acknowledgments}

The research was accomplished at Bialystok University of Technology (grant WZ/WBIIS/2/2019) and financed from subsidies of Polish Ministry of Science and Higher Education.

\section{REFERENCES}

1. Andraka D. 2009. Evaluation of reliability of sequencing batch reactor by fault tree analysis. Pol. J. Environ. Stud. Series of Monographs, Vol. 4, 5-10.

2. Andraka D. and Dzienis L. 2013. Modelling of risk in wastewater treatment plants operation (in Polish). Rocz. Ochr. Środ., 15(2), 1111-1125.

3. Ayesha S., Balasubramanian S. and Latha K. C. 2013. A Time Series Analysis of Wastewater Inflow of Sewage Treatment Plant in Mysore, India. International Journal of Current Research 5(2), 248-253.

4. ATV-DVWK. 2000. ATV-DVWK Standards A 131E: Dimensioning of Single-Stage Activated Sludge Plants, ATV-DVWK, Water, Wastewater, Waste. Hennef, Germany.

5. Berthouex P.M. and Box G.E. 1996. Time series models for forecasting wastewater treatment plant performance. Water Res. 30, 8, 1865-1875
6. Berthouex P.M. and Hunter W.G. 1983. How to construct reference distributions to evaluate treatment plant effluent quality. J. Water Pollut. Control Fed. 55(12), 1417-1424.

7. Bever J., Stein A. and Teichman A. 1997. Advanced methods in wastewater treatment (in Polish). Projprzem-EKO, Bydgoszcz.

8. Kelley D.L. and Allison R.C. 1981. Fault Tree Analysis and Treatment Plant Instrumentation. J. Water Pollut. Control Fed., 53(1), 43-47.

9. Niku S., Schroeder E.D. and Samaniego F.J. 1979. Performance of activated sludge process and reliability-based design. J. Water Pollut. Control Assoc. 51(12), 2841-2857.

10. Niku S. and Schroeder E.D. 1981. Factors affecting effluent variability from activated sludge processes. J. Water Pollut. Control Assoc. 53(5), 546-559.

11. Niku S., Schroeder, E.D., Tchobanoglous G. and Samaniego F.J. 1981. Project Summary. Performance of Activated Sludge Processes: Reliability, Stability and Variability. United States EPA, EPA-600/S2-81-227.

12. Oliveira S.C. and Von Sperling N. 2008. Reliability analysis of wastewater treatment plants. Wat. Res. $42,1182-1194$

13. Rak J. and Pietrucha-Urbanik K. 2019. An approach to determine risk indices for drinking water - study investigation. Sustainability-Basel, 11(11), 3189; $1-11$.

14. Rak J. and Wieczysty A. 1997. Functioning of the system: wastewater treatment plant - receiver from the perspective of reliability theory (in Polish). Proc. IX National Scientific - Technical Conference: Wastewater Treatment - New Trends, Modification of Exising Plants, Sludge Disposal. Rajgród 1997, 16-24.

15. Smith D.J. 2011. Reliability, Maintainability and Risk, 8th ed. Butterworth-Heinemann, Oxford.

16. Taheriyoun M. and Moradinejad S. 2015. Reliability analysis of a wastewater treatment plant using fault tree analysis and Monte Carlo simulation. Environ. Monit. Assess. 187, 4186.

17. Tchobanoglous G., Burton F.L. and Stensel H.D. (Metcalf \& Eddy Inc). 2003. Wastewater engineering. Treatment and reuse (4th ed.). McGraw-Hill Education, New York. 